\title{
Structure-Properties Relations in Friction Stir Spot Welded Low Carbon Steel Sheets for Light Weight Automobile Body
}

\author{
Seung-Wook Baek ${ }^{1, * 1}$, Don-Hyun Choi ${ }^{1}$, Chang-Yong Lee ${ }^{1}$, Byung-Wook Ahn ${ }^{1}$, \\ Yun-Mo Yeon ${ }^{2}$, Keun Song ${ }^{2}$ and Seung-Boo Jung ${ }^{1, * 2}$ \\ ${ }^{1}$ School of Advanced Materials Science and Engineering, Sungkyunkwan University, \\ 300 Cheoncheon-dong, Jangan-gu, Gyeonggi-do 440-746, Korea \\ ${ }^{2}$ Department of Advanced Materials Application, Suwon Science College 9-10, \\ Botong-li, Jeongnam-myeon, Hwasung, Gyeonggi-do 445-742, Korea
}

Low carbon steel plates were joined by friction stir spot welding (FSSW) with lap configuration. The tool penetration depth exerted a strong effect on the failure mode of the joined samples and a weak effect on the joint shear strength. With increasing tool penetration depth, and consequently with increasing depth of the tool shoulder pressing into the top sample, the failure mode in a lap-shear test changed from brittle to ductile and concentrated near the pinhole located away from the weld towards the base metal. No mechanically mixed layer was formed between the top and bottom plates at the weld nugget due to the limited tool penetration and the fact that the pin height of the welding tool was less than the steel plate thickness. The region under the pin exhibited a fully recrystallized microstructure, with grain growth and a different texture. [doi:10.2320/matertrans.M2009300]

(Received September 2, 2009; Accepted October 8, 2009; Published January 25, 2010)

Keywords: friction stir spot welding, low carbon steel, WC-Co alloy tool, texture, tensile shear strength

\section{Introduction}

Friction stir spot welding (FSSW) is a new process that has recently received considerable attention from various industries including automotive. ${ }^{1)}$ A novel variant of the friction stir welding (FSW) process, FSSW creates a spot, lap-joint without material melting. The appearance of the resulting joint resembles that from the electric resistance spot welding (ERSW) process commonly used for auto-body assembly. The solid-state bonding and other features of the process make it inherently attractive for body assembly and other similar applications. Although the primary welding process for auto body structure assembly, ERSW can be problematic for many new, high performance, structural materials such as $\mathrm{Al}$ and $\mathrm{Mg}$ alloys, advanced high-strength steels. ${ }^{2,3)}$

So far, the majority of the research and development efforts on FSW has focused on aluminum alloys as they undergo FSW easily due to their easy deformation at relatively low temperatures (below about $550{ }^{\circ} \mathrm{C}$ ). ${ }^{4-12)}$ Furthermore, the development of FSSW for Al alloys has been quite successful. Mazda reported the first mass production application of FSSW on its 2003 RX-8. The entire Al rear door was welded with FSSW. ${ }^{13)}$ Mazda reported over $90 \%$ operation energy savings and over 40 percent capital investment reductions when compared to the ERSW of Al alloys.

Nevertheless, steel remains the primary material for body structures of all high-volume, mass-produced cars. The success of FSSW in $\mathrm{Al}$ alloy body structures has led to tremendous interest in applying the technology to steel plate welding. However, past research and development on linear FSW have shown that the application of FSW to steels is much more difficult than to $\mathrm{Al}$ alloys. The technical difficulties stem from the following two fundamental aspect of the FSW process: FSW of steel must operate at much

\footnotetext{
${ }^{* 1}$ Graduate Student, Sungkyunkwan University

${ }^{* 2}$ Corresponding author, E-mail: sbjung@skku.ac.kr
}

higher temperatures than for aluminum alloys, and it requires much higher mechanical loading for plunging and stirring. These technical difficulties are also expected for FSSW. ${ }^{14,15)}$ The high-volume, high-speed, and cost-conscious requirements of auto-body assembly lines make the development of FSSW even more challenging.

The present study applies FSSW to low carbon steel plate using a WC-Co alloy tool, with the following two goals. The first is to investigate the influence of one parameter-tool penetration depth-on the mechanical shear strength and failure mode of the welded joints. We varied tool penetration depth because it has been previously suggested that this has an important effect on joint properties. ${ }^{16)}$ The variation of the tool penetration depth also varies the depth with which the rotating tool shoulder presses onto the top sheet, thereby affecting that region's microstructure. The second goal of this work is to analyze in detail the microstructure of a representative joint with an insertion depth of $0.30 \mathrm{~mm}$, in order to explain the mechanism of this new joining process.

\section{Experimental Procedure}

The base material used for the welding was $0.6 \mathrm{~mm}$-thick, $30 \mathrm{~mm}$-wide, $100 \mathrm{~mm}$-long steel plates sheared from a commercial, hot annealed coil, with a chemical compositions of Fe-0.001C-0.01Si-0.14Mn-0.012P-0.007S (all compositions are mass \%), an ultimate tensile strength of $340 \mathrm{MPa}$ and an elongation of $44 \%$. The shear joints were made in a lap configuration. Two sheets were overlapped by $30 \mathrm{~mm}$. To prepare samples for joining, two sheets were affixed into the welding instrument using a fixture. The WC-Co alloy tool had a shoulder diameter of $13.5 \mathrm{~mm}$, a pin diameter of $8.5 \mathrm{~mm}$, a pin height of $0.5 \mathrm{~mm}$ and a weld tilt angle of $0^{\circ}$.

The welding parameters of FSSW are summarized in Table 1. Each joint was examined with optical microscopy (OM) and scanning electron microscopy (SEM) equipped with energy dispersive spectrometry (EDS) and electron 
Table 1 Welding parameters of FSSW.

\begin{tabular}{cc}
\hline Tool Rotation Speed (RPM) & Tool Penetration Depth $(\mathrm{mm})$ \\
\hline 1600 & $0.12 \sim 0.30$ \\
\hline
\end{tabular}

backscattering diffraction (EBSD). The metallurgical inspections were performed on a cross-section of the joint after polishing and etching with a nital solution. The mechanical properties of the spot welds were characterized tensile shear testing. The tensile shear test was carried out at room temperature at a crosshead speed of $1 \mathrm{~mm} \cdot \mathrm{min}^{-1}$.

\section{Result and Discussion}

Figure 1 shows the effect of pin penetration depth on the shear strength of the joints. The error bars in the figure represent the standard deviation for the test data. The maximum shear strength was shown at a penetration depth of $0.3 \mathrm{~mm}$. The shear strength was increased up to an

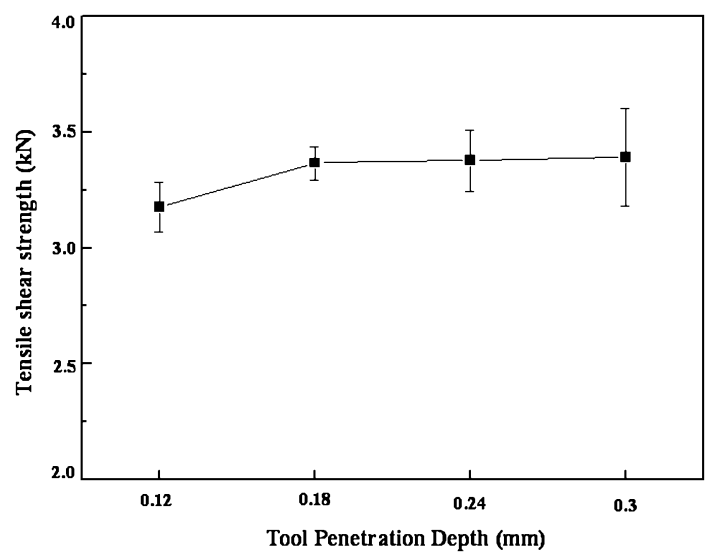

Fig. 1 Tensile shear strength of joints according to tool penetration depth. insertion depth from 0.12 to $0.18 \mathrm{~mm}$. However, as the insertion depth exceeded $0.18 \mathrm{~mm}$, the shear strength increased slightly up to the insertion depth of $0.3 \mathrm{~mm}$.

Figure 2 shows photographs of the failure surfaces of the lap shear specimens joined at different pin insertion depths. The figure also gives the exact shear strength of the displayed samples. While the difference in the lap-shear strength between these specimens was relatively small, the failure mode was strongly affected by increasing tool penetration depth. In the sample with a tool insertion depth of $0.12 \mathrm{~mm}$, fracture occurred at the interface between the top and bottom surfaces. However, as the tool penetration depth exceeded $0.18 \mathrm{~mm}$, the failure location shifted further away from the base metal with increasing depth. Failure occurred in the top sheet, midway through the section that was under the tool shoulder. In the bonded area of the joint, the bonded area was the same for the pin penetration depths of both $0.12 \mathrm{~mm}$ and $0.18 \mathrm{~mm}$. However, as the tool insertion depth exceeded $0.18 \mathrm{~mm}$, bonded area was slightly widened to a maximum of $187.62 \mathrm{~mm}^{2}$ at a tool penetration depth of $0.3 \mathrm{~mm}$. These result suggested that the increased lap-shear strength between these samples is related with the bonded area under the tool shoulder region.

Macroscopic overviews of the cross-section of each joint are shown in Fig. 3. In all samples, the top and bottom steel sheets were compressed together to form a joint interface. The decrease in the gap at the joint edge with increasing tool penetration depth suggested that it affected the joint strength and fracture location. A white layer with bilaterally symmetrical shape was observed at the top sheet in all samples. These layers were assumed to be related with the phase transformation of the steel sheets or with the reaction between the tool and steel sheets. The line evident across the middle region of the joint was attributed to the interface between the top and bottom steel sheets.
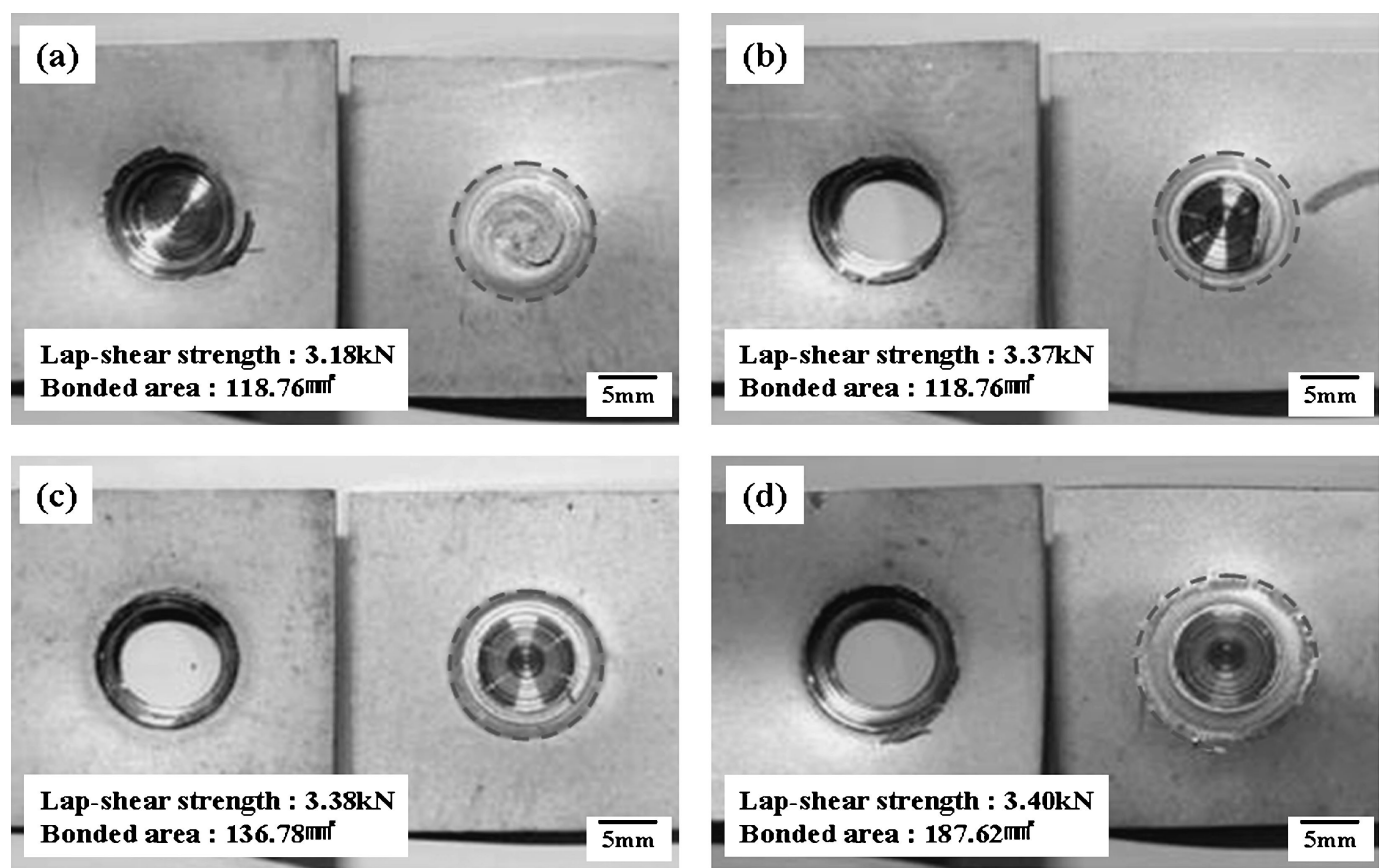

Fig. 2 Fracture photograph images after tensile shear testing at the following tool penetration depths: (a) $0.12 \mathrm{~mm}$, (b) $0.18 \mathrm{~mm}$, (c) $0.24 \mathrm{~mm}$, and (d) $0.30 \mathrm{~mm}$. 

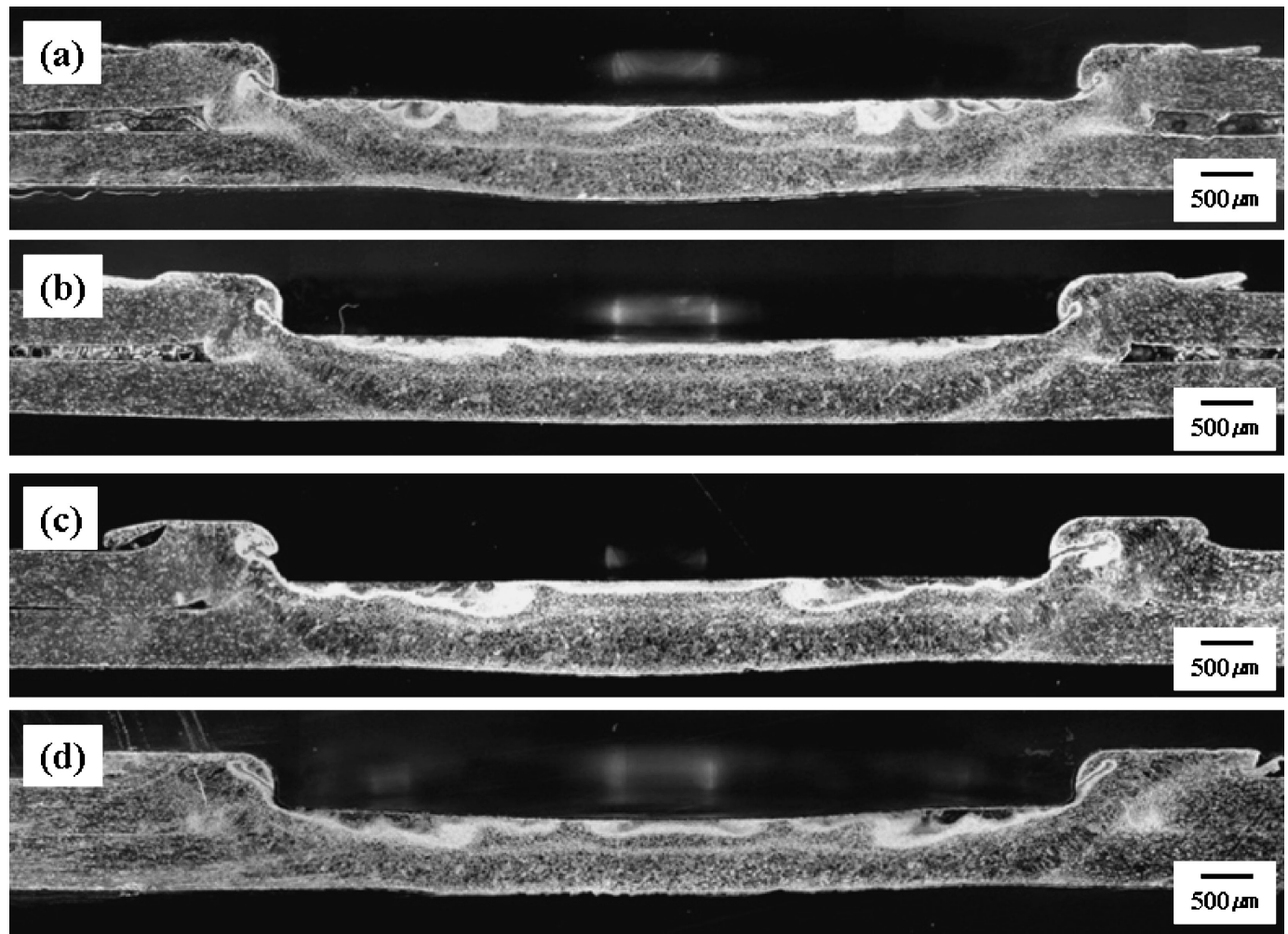

Fig. 3 Optical macro cross-sectional images at the following tool penetration depths: (a) $0.12 \mathrm{~mm}$, (b) $0.18 \mathrm{~mm}$, (c) $0.24 \mathrm{~mm}$, and (d) $0.30 \mathrm{~mm}$.
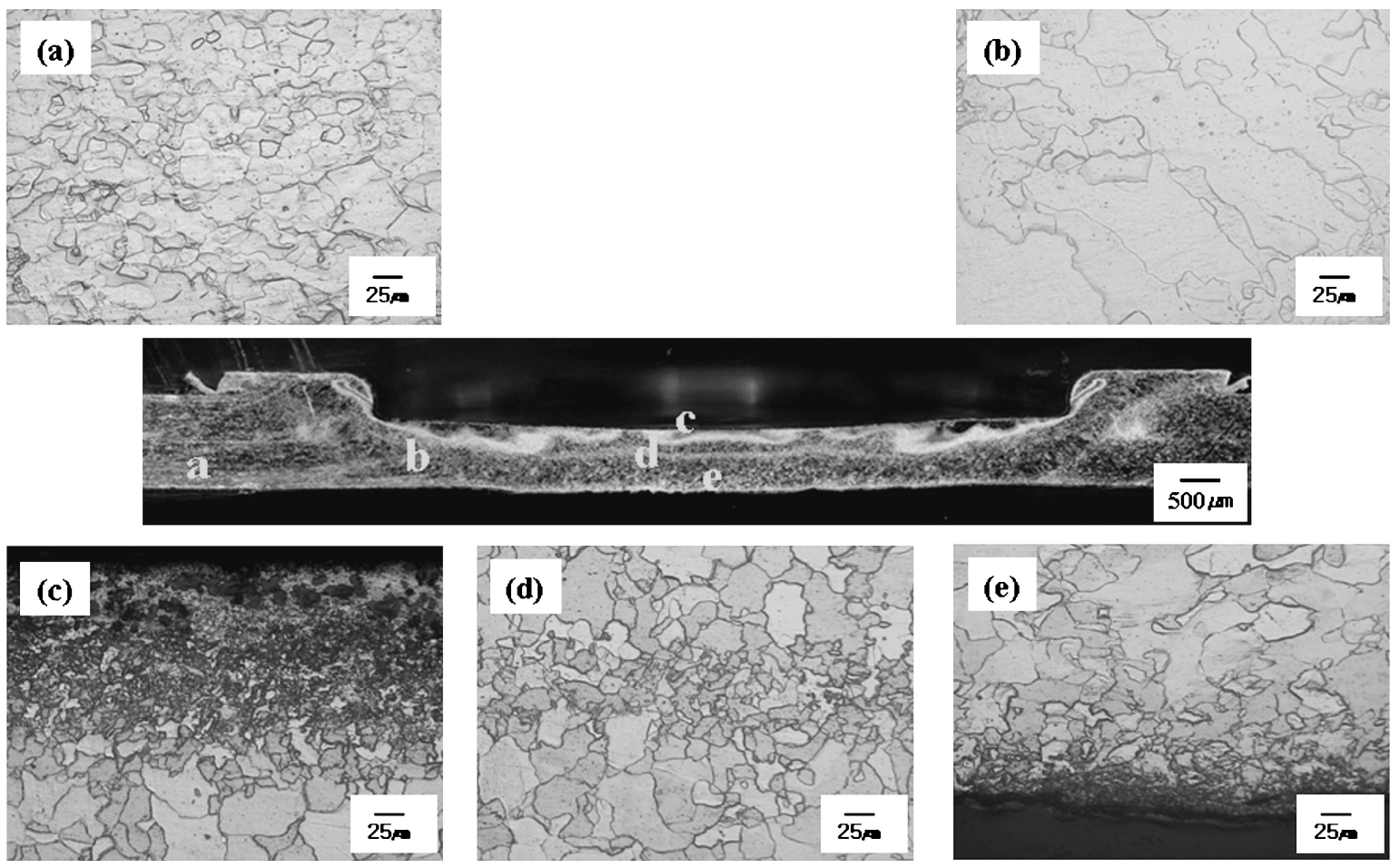

Fig. 4 Optical microstructure of the FSSW joint: (a) base metal, (b) region under shoulder, (c) top region under pin, (d) middle region under pin, (e) bottom region under pin.

Figure 4 shows the representative grain distribution in the base metal (a), and in the regions under shoulder (b) and under the pin (c)-(f) of tool penetration depth $0.30 \mathrm{~mm}$ joint.

The base material microstructure consisted of annealed ferrite phase grains, while coarse grains were observed in the region under the shoulder. This region was assumed to be the heat affected zone, in which grains were grown due to friction heat. In the region under the pin, the top, middle and bottom regions exhibited different microstructures. Very fine grains were observed in the top region (Fig. 2(c)). The white layer 

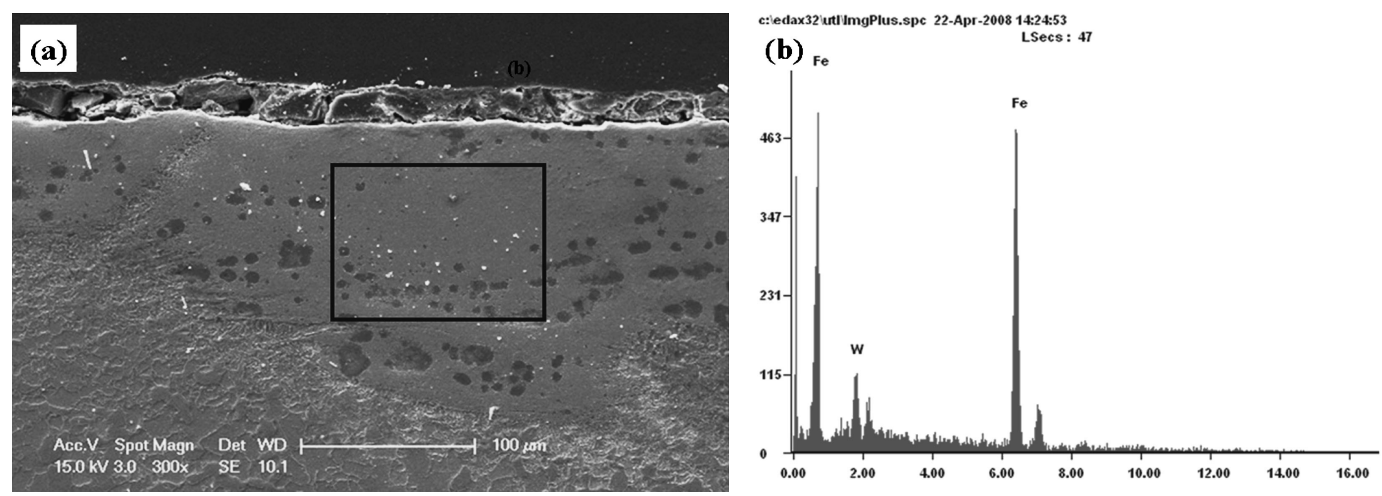

Fig. 5 Low magnification SEM micrograph of the discolored region in the FSSW joints: (a) SEM micrograph and (b) EDS result.
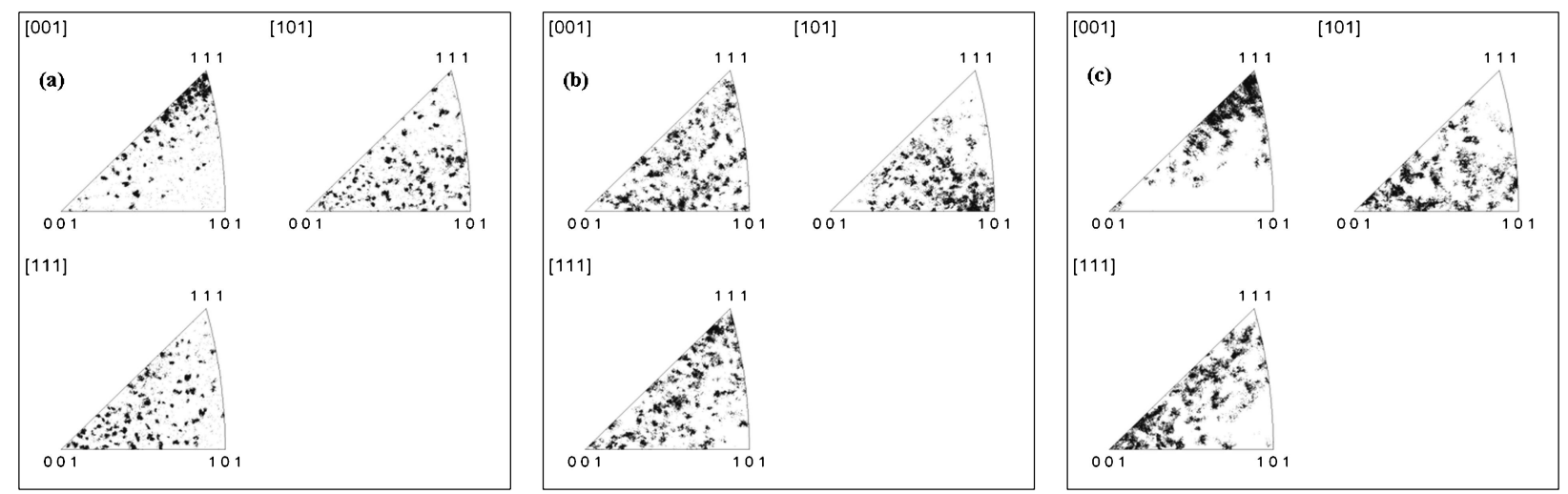

Fig. 6 Inverse pole figures of joint: (a) base metal, (b) top region in joint, (c) bottom region in joint.

in the top sheets, as aforementioned, exhibited a different microstructure from the other region.

Figure 5 shows an SEM image and the result of EDS analysis in this region. The composition of this region was $15.21 \mathrm{mass} \% \mathrm{~W}$ and 84.79 mass $\%$ Fe, suggesting that this region was generated by wear of the WC-Co tool during welding. The middle region exhibited fully metallurgical bonding. Very fine microstructures were shown between the top and bottom sheets. As the pin did not penetrate the bottom sheet, the two sheets were not bonded by mechanical stirring, in contrast with the conventional FSSW process. However, due to friction heat and tool compression, diffusion occurred between the top and bottom sheets and they were bonded. Therefore, these fine microstructures were assumed to have resulted from diffusion between the top and bottom sheets. Finally, the bottom region exhibited coarse grains, similar to that of the top region.

The joint microstructure was further investigated with EBSD analysis. Figure 6 shows inverse pole figures obtained from the base metal, and the top and bottom sheets in the joint. These inverse pole figures revealed directions of [001], [101], and [111]. Figure 6(a) shows an inverse pole figure of the base metal, demonstrating the base metal's strong $\{111\}\langle 001\rangle$ texture. This strong texture was attributed to the rolling process and annealing. Due to recrystallization, the $\{101\}\langle 101\rangle$ texture of the top sheet in the joint was markedly different from that of the base metal. However, its intensity was very low, it shows that nearly random texture. The bottom sheet in the joint displayed a similar inverse pole with the base metal, although its intensity was higher.
Figure 7 shows an image quality map with the misorientation angle of the base metal, and the top and bottom sheets in the joint. The microstructure is subdivided into high angle grain boundaries $\left(15-180^{\circ}\right.$ misorientation), and low angle grain boundaries $\left(2-5^{\circ}\right.$ misorientation and $5-10^{\circ}$ misorientation). The $2-5^{\circ}$ and $5-10^{\circ}$ misorientation subgrains are delineated in red and green, respectively, and the high angle grain boundaries in blue.

In case of base metal (Fig. 7(a)), it shows the annealed ferrite structure with a high angle boundary. The grain size distribution of the base metal was bimodal distribution, with somewhat smaller grains in the base metal. However, the top sheet in the joint exhibited a different microstructure from that of the base metal (Fig. 7(b)). The deformed grains with a varied grain size distribution were observed in this region. However, similar with base metal, the misorientation was consistent with a predominantly high angle boundary mixed with a little low angle boundary. The bottom sheet in the joint exhibited a similar grain structure and misorientation to those of the base metal, but with a somewhat larger grain size than that of the base metal (Fig. 7(c)).

These result revealed that very different microstructure of the top sheet in the joint from that of the base metal and the bottom sheet. The texture of the top sheet in the joint suggested that dynamic recrystallization occurred during welding, leading to the formation of a new texture in this region. Furthermore, the absence of any clear low angle boundary in the microstructure implied that fully grown grains were formed after welding. On the contrary, the bottom sheet in the joint exhibited a microstructure similar 

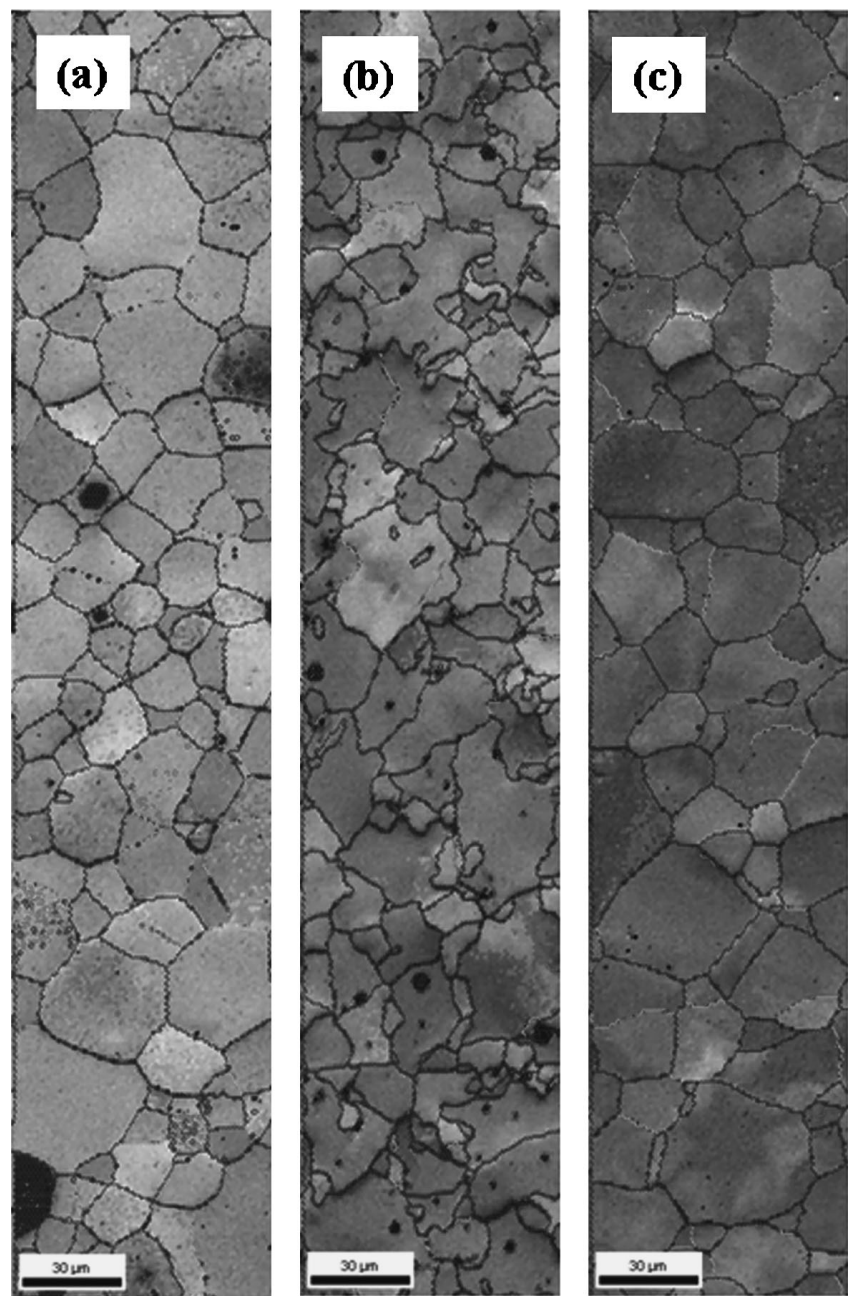

Fig. 7 IQ map of each region in joint: (a) base metal, (b) top region in joint, (c) bottom region in joint.

with that of the base metal, but with a larger grain size. These results suggested that the bottom sheet in the joint only experienced thermal cycling, without any dynamic recrystallization, during welding.

\section{Conclusion}

FSSW of low carbon steel plate was carried out as a function of tool penetration depth with a welding tool made from WC-Co alloy. The study results are summarized as follows:
(1) Sound FSSW joints were obtained without any melting of the workpiece or the mechanically mixed zone, under the specified welding conditions.

(2) With increasing tool penetration depth, the tensile shear fracture load gradually increased to a maximum of $3.40 \mathrm{kN}$ at the deepest tool penetration depth of $0.30 \mathrm{~mm}$.

(3) The detection of $\mathrm{W}$ in the top region in the joint was attributed to WC-Co tool wear, suggesting that worn tool materials were intermixed in the joint during welding.

(4) Regarding the microstructural properties of the joint, dynamic recrystallization and grain growth occurred in the top sheet in the joint, while the bottom sheet only experienced thermal cycling during welding.

\section{Acknowledgment}

This work was supported by the WCU program of Korea Science \& Engineering Foundation funded by the Korean government (MOEHRD) (Grant No. R32-2008-000-10124-0).

\section{REFERENCES}

1) R. Hancock: Weld. J. 83 (2004) 40.

2) H. Oikawa, G. Murayama, T. Sakiyama, Y. Takahashi and T. Ishikawa: NIPPON STEEL TECHNICAL REPORT No. 95 January (2007).

3) D. J. Spinella, J. R. Brockenbrough and J. M. Fridy: Weld. J. 84 (2005) 34-40.

4) C. G. Rhodes, W. M. Mahoney and W. H. Bingel: Scr. Metall. 30 (1997) 69-75.

5) K. E. Knipstrom and B. Pekkari: Weld. J. 76 (1997) 55-57.

6) W. M. Mahoney, C. G. Rodes, J. G. Filntoff, R. A. Spurling and W. H. Bingell: Metall. Mater. Trans. A 20A (1998) 1955-1964.

7) L. E. Murr, G. Liu and J. C. McClure: J. Mater. Sci. 33 (1998) 12431251.

8) L. E. Murr, G. Liu and J. C. McLure: J. Mater. Sci. Lett. 16 (1997) 1801-1803.

9) K. V. Jata, K. K. Sankaran and J. J. Rushau: Metall. Mater. Trans. A 31A (2000) 2181-2192.

10) J. C. Dawes and W. M. Thomas: Weld. J. 75 (1996) 41-45.

11) R. W. Fonda and J. F. Bingert: Metall. Mater. Trans. A 35A (2004) 1487-1499.

12) Y. S. Sato, H. Kokawa, K. Ikeda, M. Enomoto, S. Jorgan and T. Hashimoto: Metall. Mater. Trans. A 32A (2001) 941-948.

13) Mazda News Release, February 27, (2003) http://www.mazda.com/ publicity/release/2003/

14) Y. Hovanski, M. L. Santellab and G. J. Grant: Scr. Mater. 57 (2007) 873-876.

15) D. H. Choi, C. Y. Lee, B. W. Ahn, J. H. Choi, Y. M. Yeon, K. Song, H. S. Park, Y. J. Kim, C. D. Yoo and S. B. Jung: Int. J. Ref. Met. Hard Mater. 27 (2009) 931-936.

16) D. Mitlin, V. Radmilovic, T. Pan, J. Chen, Z. Feng and M. L. Santella: Mat. Sci. Eng. A 441 (2006) 79-96. 